\title{
Techno-Economic Assessment of BIPV Systems in Three Cities of Iran
}

\author{
Farivar Fazelpour ${ }^{1}$, Niloufar Ziasistani ${ }^{2, *}$, Parsa Nazari ${ }^{3}$, Pouria Nazari ${ }^{4}$ and Nastaran Ziasistani ${ }^{5}$ \\ 1 Department of Energy Systems Engineering, South Tehran Branch, Islamic Azad University, Tehran 11369, \\ Iran; f_fazelpour@azad.ac.ir \\ 2 Department of Mechanical Engineering, South Tehran Branch, Islamic Azad University, Tehran 11369, Iran \\ 3 Department of Industrial Engineering, South Tehran Branch, Islamic Azad University, Tehran 11369, Iran; \\ parsanazari@live.com \\ 4 Department of Material Engineering, Science and Research Branch, Islamic Azad University, Tehran 11369, \\ Iran; pourianazari@hotmail.com \\ 5 Sama Technical and Vocational Training College, Islamic Azad University, Shariati Branch, \\ Tehran 11369, Iran; nastaranziasistani@gmail.com \\ * Correspondence: niloozia2020@gmail.com; Tel.: +98-921-671-6332 \\ + Presented at the 2nd International Research Conference on Sustainable Energy, Engineering, Materials and \\ Environment (IRCSEEME), Mieres, Spain, 25-27 July 2018.
}

Published: 2 November 2018

\begin{abstract}
In all over the world, huge parts of energy are consumed by buildings. Building integrated photovoltaic (BIPV) systems have attracted much attention with the purpose of providing energy demand of buildings. This paper introduces the examinations of BIPV system on a residential building under different climatic conditions of Iran by considering different PV modules. The building orientation has been analysed in order to find higher efficiency rate of PV modules through DesignBuilder. It was found the maximum rate of energy generation for all three cities occurs in south side of the building. Also for Tehran and Tabriz the minimum ratio of energy consumption is at the angle of $180^{\circ}$ while for Bandar Abas it is in north side. Moreover, applying Cd-Te modules contribute to reducing payback time.
\end{abstract}

Keywords: BIPV; energy performance; economic analysis; DesignBuilder

\section{Introduction}

Building integrated photovoltaic (BIPV) system has been analysed in different sketches of the world with climate diversity, to set examples of these studies, Sorgato et al. considered the BIPV system in six Brazilian cities by introducing different PV modules in various parts of building. BIPV was found to be economically justifiable [1]. Hudișteanu et al. measured the same PV system in various locations but in temperate area. The achieved results by TRNSYS were analyzed in order to improve the profitability of photovoltaic system [2]. Also in some other articles, and it is worth mentioning that in some countries (India), there is enough solar energy that just a small amount of that, could be reasonable for the whole country's power needs. So it makes the government to think about introducing operations due to developing industry [3]. In this study, BIPV system has been considered in three different cities of Iran including Tehran, Bandar Abas and Tabriz in a four-story residential building with a floor area of $270 \mathrm{~m}^{2}$. In order to reach the most comprehensive result, it has been decided to utilize all three photovoltaic modules which contains: monocrystalline, polycrystalline and thin film. It is worth mentioning the investigations have been simulated through DesignBuilder software on one side of building in different orientations in each city. 


\section{Methodology}

In this paper the effects of multiple parameters have been studied including types of PV panels and orientations on electricity generation and energy consumption of BIPV in different climatic conditions. DesignBuilder software which integrates EnergyPlus engine was used as software for simulation.

The residential building has been examined which has four floors with an area of $270 \mathrm{~m}^{2}$ per floor that each one includes 2 bedrooms, 2 restrooms, a kitchen, a bathroom and a dining room. To make the article more comprehensive, three different cities have been selected.

Influences of building's orientation on energy consumption and transmitted solar gain for Tehran, Bandar Abas and Tabriz have been investigated.

Building has examined in four main geographic directions to find the most productive mode and finally economic analyses has done for most productive direction through discounted payback time method (DPBT), that is describing the minimum time taking to recover investment cost.

\section{Result and Discussion}

In this section the results are presented and have been discussed.

\subsection{Transmitted Solar Gain}

Effects of building orientation on transmitted solar gain for Tehran, Tabriz and Bandar Abas were examined and the details are as below:

The highest rate for Tehran is at the angle of $120^{\circ}$ which is equal to $54,703.68 \mathrm{w} / \mathrm{m}^{2}$ as well as the lowest rate is equivalent to $33,237.65 \mathrm{w} / \mathrm{m}^{2}$ at $0^{\circ}$. Additionally, Bandar Abas solar gain is describing that the highest achieved at $255^{\circ}$ which is $45,373.21 \mathrm{w} / \mathrm{m}^{2}$ and the least is $29,512.82 \mathrm{w} / \mathrm{m}^{2}$ at the angle of $0^{\circ}$. Moreover, for Tabriz the maximum solar gain obtained at $120^{\circ}$ in the amount of $37,387.21 \mathrm{w} / \mathrm{m}^{2}$ also the minimum rate is at $0^{\circ}$ and equal to $24,719.28 \mathrm{w} / \mathrm{m}^{2}$.

\subsection{Energy Consumption}

The effect of building orientation on energy consumption for three mentioned cities has been simulated. The used energy for Tehran is between $61,055.52 \mathrm{kWh}$ and $67,326.32 \mathrm{kWh}$ which the highest is at the angle of $285^{\circ}$ and the least is at $180^{\circ}$. These amounts for Bandar Abas is between $81,271.5 \mathrm{kWh}$ and $87,480.9 \mathrm{kWh}$ which the most and least amounts occur at $255^{\circ}$ and $0^{\circ}$. Also these used energies are among $71,091.29 \mathrm{kWh}$ and $66,498.13 \mathrm{kWh}$ for Tabriz that the highest amount is at the angle of $60^{\circ}$ and the lowest is in $180^{\circ}$.

\subsection{Energy Generation}

Three types of panels have been considered for Tehran, Bandar Abas and Tabriz. According to the charts, produced electricity has been compared and examined at $0^{\circ}, 90^{\circ}, 180^{\circ}$ and $270^{\circ}$.

Monocrystalline panel: As it is expressed by Figure 1, the maximum production by Mono-Si panels occurs when BIPV is south oriented and the minimum of it takes place when BIPV is north oriented. In addition, their amounts are as follows:

- Tehran is between $13,462.67 \mathrm{kWh}$ and $39,801.66 \mathrm{kWh}$.

- Bandar Abas is between 16,817.01 kWh and 29,139 kWh.

- Tabriz is between $13,462.67 \mathrm{kWh}$ and $25,807.84 \mathrm{kWh}$. 


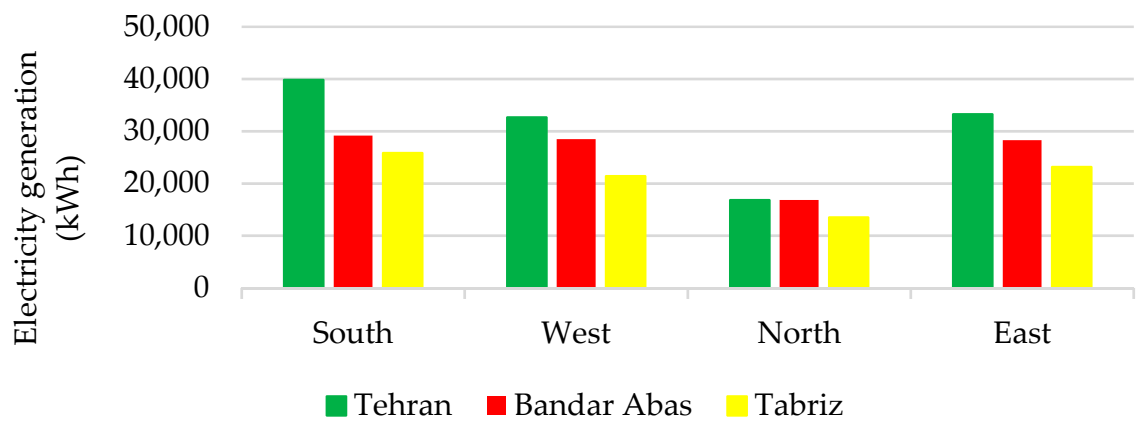

Figure 1. Electricity generation for Mono-Si for different sides.

Polycrystalline panel: As shown in Figure 2, the maximum amount of energy produced by Poly-Si for is when the BIPV side faces south side and the minimum of it happens when the BIPV side faces north. Also their variable amounts are presented as below:

- Tehran is variable between $15,621.67 \mathrm{kWh}$ and 36,996.76 kWh.

- $\quad$ Bandar Abas is between 15,631.89 kWh and 27,085.52 kWh.

- $\quad$ Tabriz is between $12,513.93 \mathrm{kWh}$ and $23,989.12 \mathrm{kWh}$.

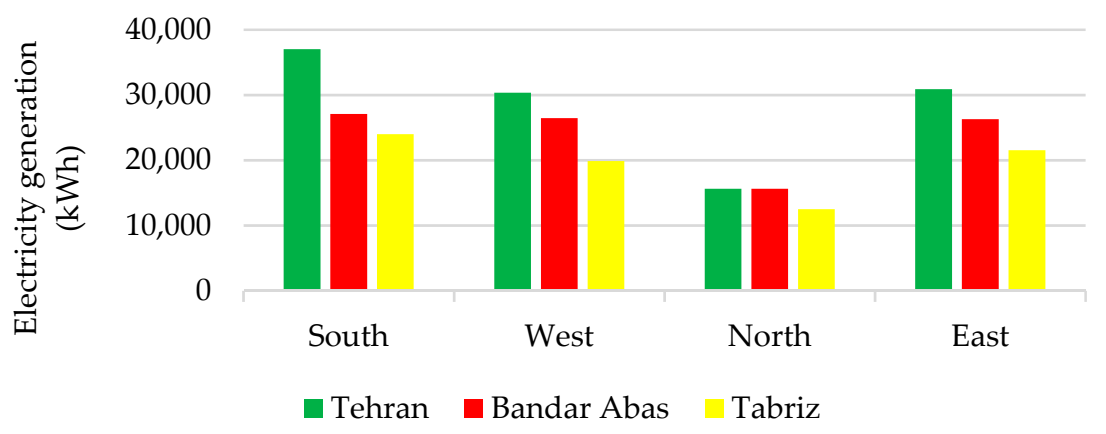

Figure 2. Electricity generation for Poly-Si for different sides.

Thin film panel: Analyses show in Figure 3, that produced electricity by thin film panels is like two previous cases. It means that the maximum production happens when BIPV is south facing and when BIPV is north facing, production reaches to the lowest level for cities Tehran, Bandar Abas and Tabriz.

- Tehran is between 15,032.1 kWh and 7452.36 kWh.

- Bandar Abas is between 11,753.3 kWh and 20,365.6 kWh.

- Tabriz is between 9,408.97 kWh and $18,036.93 \mathrm{kWh}$.

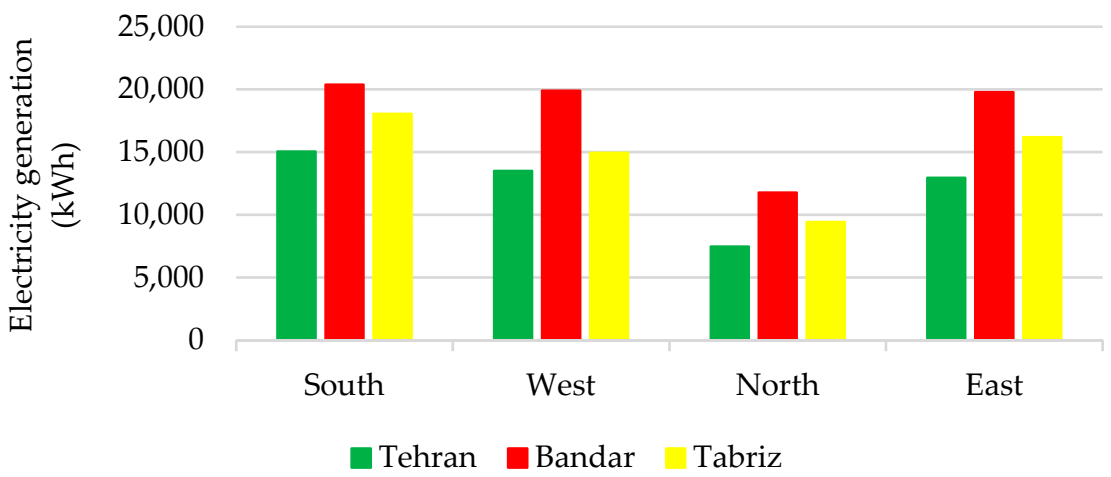

Figure 3. Electricity generation for Cd-Te for different sides. 


\subsection{Economic Analysis}

Payback method shows period of time that is needed to recover the cost. So according to the results such as energy generation, energy consumption and also panels costs and prices of installation as one of the necessary parameters, there are enough information in order to calculate Payback time. As it is mentioned in energy generation part, the highest amount of energy generated occurs in the southern side of the building, therefore economic analysis has done due to the calculations in this direction.

The outcomes of discounted payback time (DPBT) are shown in Figure 4. As it could be deduced from the chart, the payback time of Tehran for each three modules monocrystalline, polycrystalline and thin film are equal to 14, 10 and 1 years. Furthermore for Bandar Abas, the payback time in these modules respectively are equal to 31,18 and 10 years. As the last city in this part, Tabriz, the minimum time to recover the costs in three mentioned modules are up to 33, 23 and 14 years.

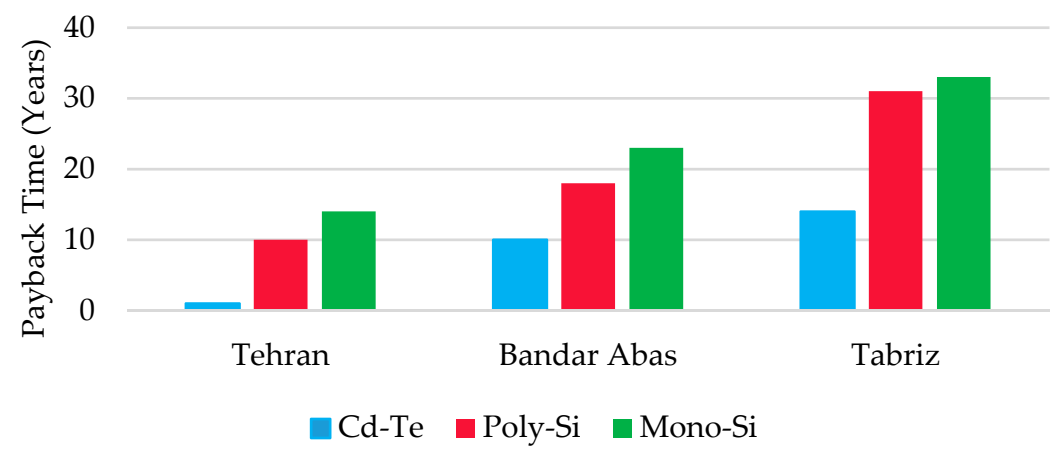

Figure 4. Comparing payback time of Cd-Te, Poly-Si and Mono-Si in Tehran, Bandar Abas and Tabriz.

\section{Conclusions}

This paper has studied the energy and economic performance of BIPV, also has considered some effective factors like transmitted solar gain, climatic conditions (Tehran, Bandar Abas, Tabriz), building orientation and photovoltaic type. The results of this investigation show that:

- In all three cities northern side of building has the lowest transmitted solar gain.

- Energy consumption depends highly on building orientation. The minimum energy demand for Tehran and Tabriz is on the south side of BIPV while for Bandar Abas is on the north side of building. The maximum energy demand for Tehran is at an angle of $285^{\circ}$, for Tabriz occurs at $60^{\circ}$ and for Bandar Abas is at $255^{\circ}$.

- The minimum annual electricity generation for Tehran, Tabriz and Bandar Abas in three types of photovoltaic happens when the building orientation is $0^{\circ}$. Also simulation shows when the $\mathrm{BIPV}$ is facing south, the electricity generation for Mono-Si, Poly-Si and Cd-Te is maximum.

- Payback time for Tehran, Bandar Abas and Tabriz has reduced by applying Cd-Te modules also the highest DPBT for all three cities were calculated by considering Mono-Si.

\section{References}

1. Sorgato, M.J.; Schneider, K.; Rüther, R. Technical and economic evaluation of thin-film CdTe buildingintegrated photovoltaics (BIPV) replacing façade and rooftop materials in office buildings in a warm and sunny climate. Renew. Energy 2018, 118, 84-98, doi:10.1016/j. renene.2017.10.091.

2. Hudișteanu, S.V.; Popovici, C.G.; Mateescu, T.D.; Cherecheș, N.C. Efficiency analysis of BIPV systems for different locations in Romania. Energy Procedia 2017, 112, 404-411, doi:10.1016/j.egypro.2017.03.1089.

3. Shukla, A.K.; Sudhakar, K.; Baredar, P.; Mamat, R. Solar PV and BIPV system: Barrier, challenges and policy recommendation in India. Renew. Sustain. Energy Rev. 2018, 82 Pt 3, 3314-3322, doi:10.1016/j.rser.2017.10.013. 